\title{
Using Google Docs and Forms to Develop Enhanced e-debates in English for Elementary School Pupils
}

\author{
Panagiotis Georgalas, Adamos Anastasiou, Despina Androutsou
}

\begin{abstract}
This study aims at the development of elementary school pupils' critical thinking, along with their debate and writing skills in the English language. This model uses collaborative texts in order to increase the interaction not only among the pupils but also between the teacher and the pupils. It is based on targeted exploitation of the Google Drive platform. Several team-working tools are used such as Google Docs and Questionnaires. The whole educational approach tends to be student-oriented, since the pupils themselves are both the creators and the evaluators of the educational outcomes. The method was applied to 46 th grade pupils of a model primary experimental school in Greece. Taking into consideration the results of the research, we conclude that the targeted usage of some of the new Web 2.0 educational tools could broaden the existing educational horizons and become beneficial to the development of new skills and abilities on students' part.
\end{abstract}

Index Terms - collaborative texts, group debate, primary school pupils, , Web 2.0.

\section{INTRODUCTION}

Nowadays, the implementation of modern technologies in education creates new pedagogical streams and approaches. When it is properly embedded in classroom scenarios, it boosts creativity and favors the innovative thinking of young people (Anderson, 2007). At the same time, knowledge becomes more efficient when the students built-up the new knowledge by creating their own products which get an added value for them and their classmates. As a result, an authentic learning environment must simulate everyday life (Kritzenberger, Winkler \& Herczeg, 2002). Especially for second language acquisition, the development of reading, writing, listening and creative skills through the utilization of modern technological tools is considered essential (Ybarra \& Green, 2003). As a matter of fact, the educator needs to find, evaluate and select suitable educational software and adapt it to the local educational system and needs of the pupils.

A virtual classroom tool, such as Blackboard Collaborate, or a videoconferencing tool, such as Skype, would allow participants to take part in a debate from anywhere in the world - in much the same way as many of the debates on news programmes. Using these tools also allows debates to include outside parties, a series of debates on the criminal justice system, for example, could have students debating with lawyers, convicted criminals and victims of crime, and allow each to present their view, perhaps even anonymously

Georgalas Panagiotis, Junior High School Teacher in Athens, Greece Anastasiou Adamos, Elementary School Teacher and Adjunct Faculty Instructor, Thessaloniki, Greece

Androutsou Despina, Elementary School Teacher and Adjunct Faculty Instructor, Thessaloniki, Greece
(Glover, 2014). Following these directives, we noticed that the creation of collaborative debate texts in primary school can lead to the development of their writing skills and vocabulary acquisition.

\section{THE WEB 2.0 TOOLS}

The diffusion of knowledge in a school class and the interaction among students can be significantly boosted through the usage of the Web 2.0 educational tools. They have managed to offer us the possibility to break educational barriers, since nowadays we have the opportunity to change the way we tell a story, the teaching method in a classroom or the teaching for individual learning (Alexander, 2006). A large variety of specialized applications can be used simultaneously or in a complementary way with other educational tools in a class. As the cost of ICT infrastructure becomes lower and the amount of data that can be exchanged every second keeps growing up, the pupils are able to have simultaneous access to Web 2.0 platforms. Especially for young ages, Internet safety should also be provided through a children-friendly network and the careful usage of the computer school lab. The fact that modern educational tools are also available in the local languages results in making the access to them easier, especially for children of primary school. The effective usage of Web 2.0 tools can lead to faster and deeper diffusion of knowledge in a classroom. Furthermore, a positive interaction and exchange of knowledge and ideas can be easily achieved.

The Google Docs application allows access from any computer and eases the ability to collaborate by sharing a document with others as viewers or collaborators, or by publishing it on the web (Conner, 2008). Google Docs supports synchronous editing and comment writing, and saves versions of the document, options that afford real-time collaborative learning. The Educational Edition of Google Apps is free; it was built especially for schools, universities and nonprofit organizations, and does not require downloading new software or buying hardware (Oishi, 2007). Sharing content using the application is very simple, may facilitate collaboration, allows peer review of academic materials, and affords collective generation of knowledge (Educause Learning Initiative, 2008). Similar to Wikis, Google Docs enables collaboration by editing a document written by other students, and by suggesting modifications through comment writing, without editing the document itself. In addition, the revision history function of Google Docs contributes to more transparency and ease of use among collaborators in the writing process, and the fact that students know their changes could be automatically saved and 
previous versions could be retrieved makes them more willing to make changes, and alleviates the tension between individual and collaborative writing (Kessler et al. 2012).

Finally, the polls - questionnaires have become a very widespread and easy Web 2.0 tool to use. Using their facilities, the members of a group can express their opinions or vote for / against various issues. Special inhibited processes can assure the validity of the voting. For instance, they eliminate the possibility for a member of a group to vote twice for or against the same issue. The polls can be used creatively in education because of their convenience to get set up, used, controlled and managed. They also enable the teacher - educator to collect the students' conclusions about an issue very quickly. Moreover, they give the opportunity to observe the validity of a study concurrently, checking, for example, if all the questions have been answered by all students. Google platform provides easy creation and distribution of questionnaires to be used in a classroom.

\section{THE DEBATE IDEA}

Passive educational techniques are thought to be less productive than active learning. One of the methods which can be used effectively for class sessions is preparing for and participating in a debate as a teaching/learning tool (González, Gonzalez, \& Bermejo, 2010). Debate is a method with a long history and it works very well without technology, however technology can bring advantages to the process. Without technology, debate is generally only practical as a 'live' activity with participants and audience in the same room at the same time, but technology can extend the use of debate into situations where it isn't possible (or desirable) to have everyone together in the same physical environment (Glover, 2014).

More particularly, teachers can use debates in almost any discipline, include students of all reading levels, and, when properly orchestrated, help students comprehend important and complex issues (Evans, 1993). Using students' natural talent of arguing, we can channel student energy into a positive learning assignment. Debates offer that natural avenue for teachers to facilitate analytical thinking (González, Gonzalez, \& Bermejo, 2010).

Student debates are effective ways to foster cooperation, critical thinking, and enthusiasm for learning among middle school students (Evans, 1993). According to researches, debate can become a valuable educational tool as it assists in the development of critical thinking and communication skills, whereas it can boost the creativity and the competition skills and strengthen the feeling of responsibility both of the educators and the students (Garett, Schoener \& Hood, 1996). As for computer assisted educational debate approaches, several attempts have been made for the creation of a user-friendly debate environment (De Chiara, Manno \& Scarano, 2010). In related studies like the one that took place in Finland (Marttunen \& Laurinen, 2001), a considerable improvement concerning the ability of students to develop compound arguments during a debate was observed. In another educational approach, a specialized software application named KIE was used to help students develop their debate skills. This method also had a very positive impact on students (Bell, 2000). Finally, as far as the field of second language acquisition is concerned, research results show that argumentation in classrooms can considerably boost students' language skills (Gilardoni, 2010). Moreover, results revealed that the students felt that their interest in debate, knowledge of the topic, and reinforcement of the previous knowledge had improved following participation in the debate. Debate was a useful tool in teaching health economics to dental students (Khan S. Aet al., 2012).

Debates enable students to work cooperatively, engage in conducting comprehensive research into the topic, brainstorm ideas, gather supporting evidence, develop vocabulary and read to support an opinion. Through researching students are taking notes to summarize, to question, and to clarify information. Students are identifying the main idea, deleting less important information, collapsing, categorizing, and labeling information. Questioning allows students to explain and to explore additional facts for clarification purposes. Moreover, debates allow students to develop the critical spirit and to get a personal opinion.

Debates allow students to become more proficient in speaking, researching, reading, and writing skills, and they promote reasoning as well as communication skills. This tool allows collaborative learning, delegation of tasks, and developing leadership and team-skills. Debates provide the incentive for students and are a vehicle for students to express their opinions assertively in a respectful manner on a relevant issue or topic. As a result, debates is a funny way to develop some specific and a lot of transversal competences in university students (González, Gonzalez, \& Bermejo, 2010).

In fact, tools such as online discussion boards and forums can provide the same opportunity to include participants from a variety of locations but also allow the debate to take place over an extended period of time. This would let the participants research their responses to their opponents and take their time in crafting their own statements. An additional advantage of using these tools it that a record is automatically created and can be referred to both during and after the debate - though it is important to make sure that participants are not able to change their contributions after a response has been posted. As this is a written rather than spoken medium, the students are able to develop some different skills than they would in a traditional debate; in particular, this method encourages the development of critical writing (Glover, 2014).

\section{APPLICATION IN CLASSROOM}

The initial idea was to use the aforementioned Google Drive tools and especially Google Docs and Questionnaires in a supporting and complementary form to the 5th class elementary school English book. The basic aim was to check whether these particular tools can contribute to the improvement of students' critical thinking, the reinforcement of their ability to debate and the development of their writing and oral skills. In total, 46 pupils of the 5th class (11 years old) of a primary experimental school in Thessaloniki in Greece participated in this study.

The application in classroom lasted for 2 teaching hours. It took place in the computer lab of this model experimental 
World Journal of Research and Review (WJRR)

ISSN:2455-3956, Volume-7, Issue-6, December 2018 Pages 10-13

school and there was also a complementary use of a projector for the presentation of the project to the pupils. Through the computer network there was an extensive use of Web 2.0 tools.

The first step was to find suitable questions in English so that the pupils could be able to support their opinion. The debate subjects that were given to the pupils were: "Should schools have a dress code?", "Should school start and finish one hour later?" and "Should we have two-week extra vacations in winter and two-week extra lesson in summer?". Then the pupils were divided into two groups for each question. The task for the first group was to support the FOR opinion whereas the pupils of the second group had to support the AGAINST opinion. Every pupil had to prepare just one argument according to the question and the group that he/she had chosen.

During the next school hour, the pupils wrote their arguments in a common Google Docs text, forming FOR and AGAINST argument lists. When completed, the texts were read in the classroom and commented by the pupils.

The next step was the evaluation of the answers and the measurement of the impact to the pupils. Every pupil was reading carefully the answers that were given to a debate question that he/she didn't take part. Then he/she had to answer two questions through Google Forms. The first one was: "Before reading the answers to the debate subject my opinion was: FOR/AGAINST". The second one was "After having read the arguments of my classmates my opinion is: FOR/AGAINST".

The before and after answers were recorded and evaluated. In this way we measured the change of the pupils' opinions on the given subjects. The teacher had a role of coordinator and facilitator. He encouraged the children to discover and use the new ICT environment. He also helped them to follow the steps of the scenario, locate any possible mistakes and express their opinions.

\section{RESULTS}

At the end of the project the pupils used the polls in order to answer several questions.

Table 1. Interest of scenario: Sample 50 pupils

(Scale: 1-5 / 1: Not at all 2: Little 3: Medium 4: Quite interesting 5: Very interesting)

\begin{tabular}{|l|l|l|l|l|l|}
\hline Question & \multicolumn{5}{|l|}{ Percentages } \\
\cline { 2 - 6 } & 1 & 2 & 3 & 4 & 5 \\
\hline $\begin{array}{l}\text { Was group debate } \\
\text { interesting for you? }\end{array}$ & $0 \%$ & $4 \%$ & $12 \%$ & $40 \%$ & $44 \%$ \\
\hline
\end{tabular}

The answers above show that the majority of the pupils found the group debate scenario interesting.

Table 2. Ease of using new technologies: Sample 50 pupils

(Scale: 1-5 / 1: Very difficult 2: Difficult 3: Medium 4: Easy 5: Very easy)

\begin{tabular}{|l|l|l|l|l|l|}
\hline \multirow{2}{*}{ Question } & \multicolumn{5}{|l|}{ Percentages } \\
\cline { 2 - 6 } & 1 & 2 & 3 & 4 & 5 \\
\hline $\begin{array}{l}\text { Were Google tools easy for } \\
\text { you? }\end{array}$ & $0 \%$ & $2 \%$ & $6 \%$ & $34 \%$ & $58 \%$ \\
\hline
\end{tabular}

Based on the above findings we can conclude that nowadays 12 year-old pupils do not face serious difficulties when they use Google Docs and Questionnaires.
Table 3. English skills improvement: Sample 50 pupils (Scale: 1-5 / 1: Surely no 2: No 3: So and so 4: Yes 5: Surely yes)

\begin{tabular}{|l|l|l|l|l|l|}
\hline Question & \multicolumn{3}{|l|}{ Percentages } \\
\cline { 2 - 6 } & 1 & 2 & 3 & 4 & 5 \\
\hline $\begin{array}{l}\text { Did you improve your } \\
\text { writing skills in English } \\
\text { with this method? }\end{array}$ & $4 \%$ & $8 \%$ & $12 \%$ & $58 \%$ & $18 \%$ \\
\hline $\begin{array}{l}\text { Did you improve your } \\
\text { debate skills with this } \\
\text { method? }\end{array}$ & $6 \%$ & $12 \%$ & $22 \%$ & $38 \%$ & $22 \%$ \\
\hline
\end{tabular}

The conclusion coming up from the above answers is that the vast majority of the pupils stated that their writing skills in English were improved along with their debate skills.

Table 4. Impact of the arguments on pupils: Sample 50 pupils

\begin{tabular}{|l|l|l|l|}
\hline $\begin{array}{l}\text { What was my } \\
\text { opinion before } \\
\text { and after } \\
\text { having read } \\
\text { the arguments? }\end{array}$ & $\begin{array}{l}\text { Should } \\
\text { schools } \\
\text { have a a } \\
\text { dress } \\
\text { code? }\end{array}$ & $\begin{array}{l}\text { Should } \\
\text { school } \\
\text { start and } \\
\text { finish one } \\
\text { hour } \\
\text { later? }\end{array}$ & $\begin{array}{l}\text { Should we have } \\
\text { two week extra } \\
\text { vacations in the } \\
\text { winter and two } \\
\text { week extra } \\
\text { lesson in the } \\
\text { summer? }\end{array}$ \\
\hline $\begin{array}{l}\text { Previously } \\
\text { YES } \\
\text { Now YES }\end{array}$ & $34 \%$ & $48 \%$ & $28 \%$ \\
\hline $\begin{array}{l}\text { Previously } \\
\text { YES } \\
\text { Now NO }\end{array}$ & $4 \%$ & $6 \%$ & $12 \%$ \\
\hline $\begin{array}{l}\text { Previously NO } \\
\text { Now NO }\end{array}$ & $52 \%$ & $42 \%$ & $58 \%$ \\
\hline $\begin{array}{l}\text { Previously NO } \\
\text { Now YES }\end{array}$ & $10 \%$ & $4 \%$ & $2 \%$ \\
\hline
\end{tabular}

As it was expected, most pupils kept their original opinions, but there was also a small percent of pupils that changed their minds as they were convinced by their classmates' arguments.

\section{CONCLUSIONS}

According to the aforementioned results, it becomes obvious that the Web 2.0 technologies can boost pupils' debate skills from early ages. Moreover, they can also become a valuable educational tool as they can improve students' comprehension and writing skills in English as a foreign language. To accomplish this, a complete educational scenario is used, whereas the teacher gradually introduces young pupils to a new environment so that they can achieve a maximum exploitation of their abilities. The Google docs environment is very user friendly and it can easily be used by all students of young ages. Every pupil could intervene in a conversation and express his/her ideas. The pupils get excited when they use and exploit the new Web 2.0 collaborating text environment. By comparing their answers, they can increase their creativity.

In addition, the fact that they are placed at the center of the educational process increases their self-esteem, as they themselves are the creators of the educational material. Due to the fact that scenarios like this are presented online, students' parents are able to monitor their children's progress and participation. The inter-disciplinary approach used in this 
scenario arrears to have significant benefits for all the teachers who get involved in it as it opens new horizons to the educational process regarding many different school subjects.

\section{REFERENCES}

[1] Alexander, B. (2006). Web 2.0: A new wave of innovation for teaching and learning? Educause Review, 41(2), 32-44.

[2] Anderson, P. (2007). What is Web 2.0?: Ideas, technologies and implications for education. JISC Technology and Standards Watch, $1(1), 1-64$.

[3] Bell, P. (2000). Scientific arguments as learning artifacts: Designing for learning from the web with KIE. International Journal of Science Education, 22(8), 797-817.

[4] Conner, N. (2008). Google Apps: The missing manual. Sebastopol CA.: O'Reilly Media.

[5] De Chiara, R., Manno, L., \& Scarano, V. (2010). CoFFEE: an expandable and rich platform for computer-mediated, face-to-face argumentation in classroom.

[6] Educause Learning Initiative (2008). 7 things you should know about Google Apps. Retrieved August 12, 2018 from: https://library.educause.edu/resources/2008/3/7-things-you-should-kn ow-about-google-apps.

[7] Evans, M. D. (1993). Using classroom debates as a learning tool. Social Education, 57(7), 370.

[8] Garrett, M., Schoener, L., \& Hood, L. (1996). Debate: A teaching strategy to improve verbal communication and critical-thinking skills. Nurse Educator, 21(4), 37-40.

[9] Gilardoni, S. (2008). Argumentation in classroom interaction. Teaching and learning Italian as a second language. Analisi Linguistica e Letteraria, XVI(2), 723-737.

[10] Glover, I. (2014). Debate: An Approach to Teaching and Learning. $\begin{array}{llll}\text { Retrieved } & \text { September } & 2, & 2018\end{array}$ https://blogs.shu.ac.uk/shutel/2014/09/02/debate-an-approach-to-teach ing-and-learning/

[11] González, M., Gonzalez, I., \& Bermejo, M. (2010). The Debate as a Successful Learning Tool. Retrieved September 1, 2018 from: https://library.iated.org/view/GONZALEZ2010THE3

[12] Kessler, G., Bikowski, D., \& Boggs, J. (2012). Collaborative writing among second language learners in academic web-based projects. Language Learning \& Technology, 16(1), 91-109.

[13] Khan S. A., Omar, H., Babar, M. G., \& Toh, C. G. (2012). Utilization of debate as an educational tool to learn health economics for dental students in Malaysia. Journal of Dental Education, 76(12), 1675-1683.

[14] Kritzenberger, H., Winkler, T., \& Herczeg, M. (2002). Collaborative and constructive learning of elementary school children in experiental learning spaces along the virtuality continuum. In M. Herczeg, W. Prinz \& H. Oberquelle (Eds.), Mensch \& Computer 2002: Vom interaktiven Werkzeug zu kooperativen Arbeits- und Lernwelten (pp. 115-124). Stuttgart: B. G. Teubner.

[15] Marttunen, M., \& Laurinen, L. (2001). Learning of argumentation skills in networked and face-to-face environments. Instructional Science: An International Journal of the Learning Sciences, 29(2), 127-153.

[16] Oishi, L. (2007). Working together: Google Apps goes to school. Technology \& Learning, 27(9), 46-47.

[17] Ybarra, R., \& Green T. (2003). Using technology to help ESL/EFL students develop language skills. The Internet TESL Journal, 9(3), 1-5.

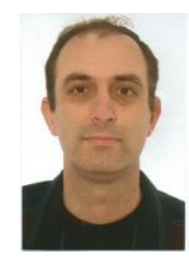

Panagiotis Georgalas has an MSc Degree in Information Technology from the University of Glasgow, Scotland and a BA degree in Physics from the University of Athens, Greece. He teaches ICT in secondary education in Greece. He has also worked for many years as an adult educator and website developer. His research interests focus on educational innovation, foreign language teaching through ICT and human-computer interaction His work has been published in both international and Greek journals, as well as in both international and Greek conference proceedings. He has taken part as a coordinator in many national and European educational school projects, like Erasmus, Comenius and eTwinning.

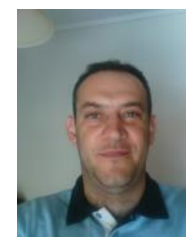

Adamos Anastasiou is a $\mathrm{PhD}$ and a Postdoctoral holder, as well as a Scientific Co-operator in Educational Administration, Leadership and Psychology in the Department of Educational and Social Policy, University of Macedonia (Thessaloniki, Greece). Moreover, apart from working as an elementary school teacher of English, he is an Adjunct Faculty Instructor (SEP) in the Hellenic Open University (EAP). His research interests focus on Educational Administration and Leadership, Vocational Education and Training, Human Resource Management (HRM) and Human Resource Development (HRD), Mentoring and Coaching, Principals' Professional Development, Training Needs \& Personality. His work has been published in both international and Greek journals, as well as in both international and Greek conference proceedings.

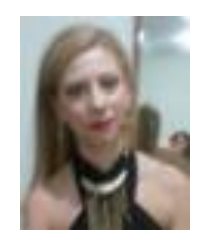

Despina Androutsou is a $\mathrm{PhD}$ holder and Scientific Co-operator in Educational Administration, Leadership and Psychology in the Department of Educational and Social Policy, University of Macedonia (Thessaloniki, Greece). Moreover, apart from working as an elementary school teacher of English, she is an Adjunct Faculty Instructor (SEP) in the Hellenic Open University (EAP). Her research interests focus on Educational Administration and Leadership, Teachers' and Students' Needs, Human Resource Management (HRM) and Human Resource Development (HRD), Mentoring and Coaching, Principals' Professional Development and Teaching English by using ICT. Her work has been published in both international and Greek journals, as well as in both international and Greek conference proceedings. 